\section{Case Reports in Neurology}

Case Rep Neurol 2021;13:211-217

DOI: 10.1159/000514243

Published online: March 22, 2021
(C) 2021 The Author(s)

Published by S. OP OPEN www.karger.com/crn

This article is licensed under the Creative Commons Attribution-NonCommercial 4.0 International License (CC BY-NC) (http://www.karger.com/Services/OpenAccessLicense). Usage and distribution for commercial purposes requires written permission.

\title{
Frontal Hypoperfusion and the Effectiveness of Perampanel in Long-Lived Patient with Lafora Disease
}

\author{
Koji Obara Erika Abe Itaru Toyoshima \\ Department of Neurology, Akita National Hospital, National Hospital Organization, \\ Yurihonjo, Japan
}

\section{Keywords}

Lafora disease $\cdot$ Myoclonus $\cdot$ Perampanel $\cdot$ Seizure $\cdot$ SPECT

\begin{abstract}
We report a long-lived patient with Lafora disease (LD). A 34-year-old woman experienced onset of seizures at the age of 11 years. She was bedridden in her early twenties due to frequent generalized tonic-clonic seizures, myoclonus, and progressive mental deterioration. Her seizures occurred all the time despite administration of multiple anticonvulsants at high doses. At the age of 31, she started perampanel, which resulted in reduction of anticonvulsants after her visible myoclonus and convulsions disappeared. Brain magnetic resonance imaging showed marked cerebral and cerebellar atrophy, and single-photon emission computed tomography using $\mathrm{N}$-isopropyl-p-[123] iodoamphetamine (IMP-SPECT) revealed significant hypoperfusion of the frontal lobe and cerebellum. We identified a W219R homozygous mutation in exon 1 of the NHLRC1 gene. Because perampanel may not only control seizures but also prevent mental deterioration in LD, we propose that perampanel should be administered from the early stage of LD.

(c) 2021 The Author(s)

Published by S. Karger AG, Basel
\end{abstract}




\section{Case Reports in Neurology}

Case Rep Neurol 2021;13:211-217

DOI: 10.1159/000514243

(c) 2021 The Author(s). Published by S. Karger AG, Basel www.karger.com/crn

Obara et al.: Long-Lived Patient with Lafora Disease

\section{Introduction}

Lafora disease (LD) is a severe progressive myoclonus epilepsy with a mode of autosomal recessive inheritance, which is caused by mutations in one of two genes, EPM2A and NHLRC1 encoding laforin and malin, respectively $[1,2]$. The symptoms typically start in the teens in those who were previously healthy and developmentally normal, and consist of visual hallucinations and myoclonic and generalized tonic-clonic seizures (GTCs) [1, 2]. Additionally, progressive mental deterioration, cerebellar ataxia, mutism, muscle wasting, and respiratory failure develop later and lead to death usually within a decade of symptom onset [1,2]. We describe a long-lived patient with LD who responded well to perampanel even in the advanced stage.

\section{Case Report}

The patient is a 34-year-old woman with onset of febrile convulsions at the age of 11 years. She was the only child from a non-consanguineous marriage. She had a normal childhood development. At the age of 12, she presented with tonic-clonic convulsions while running, followed by visual hallucinations with consciousness disturbance. At the age of 14 , she presented with frequent GTCs and myoclonic seizures, and mental deterioration. Subsequently, she was not able to walk or stand, and she could not go to school. She was diagnosed with LD after identification of Lafora bodies on axillary skin biopsy. At the age 15, she was admitted to our hospital. At that time, she was able to eat independently, move using a wheelchair, and have a simple conversation. But her myoclonus and GTCs gradually increased in frequency and speech production decreased. At the age of 22 , she became bedridden, became totally dependent in activities of daily living, and lost the ability to speak. Despite high-dose administration of multiple anticonvulsants including $360 \mathrm{mg}$ of sodium valproate, $600 \mathrm{mg}$ of zonisamide, $400 \mathrm{mg}$ of topiramate, and $15 \mathrm{mg}$ of clonazepam a day, she often experienced convulsive status epilepticus and became unresponsive to external stimuli. At the age of 23 , she was ventilated mechanically via tracheostomy due to repeated aspiration pneumonia and respiratory failure. Video-electroencephalogram (EEG) at the age of 29 showed generalized bursts of sharp waves with conjugate deviation and involuntary laughing on the monitor (Fig. 1a). The epileptiform discharges slowly subsided after the convulsion stopped and she closed her eyes (Fig. 1b). At the age of 31, administration of perampanel was started, resulting in a decrease in intractable myoclonus and GTCs without sodium valproate, zonisamide, and topiramate. At the age of 34 , she was treated with $12 \mathrm{mg}$ of perampanel and $3 \mathrm{mg}$ of clonazepam a day. Her visible myoclonus and convulsions disappeared. Her plasma concentration of perampanel was around 2,000 ng/mL. Follow-up EEG showed disappearance of epileptiform discharges (Fig. 1c). At that time, brain magnetic resonance imaging (MRI) showed frontal lobedominant cerebral atrophy and whole cerebellar atrophy with high intensity in periventricular white matter on T2-weighted images (Fig. 2a, b). Proton magnetic resonance spectroscopy (MRS) revealed a decrease in N-acetylaspartate (NAA)/creatine (Cr) and NAA/choline (Cho) in the frontal cortex compared with the occipital one. Single-photon emission computed tomography using $\mathrm{N}$-isopropyl-p-[123I] iodoamphetamine (IMP-SPECT) for the evaluation of cerebral blood flow revealed statistically significant hypoperfusion of the frontal lobe excluding the motor area with a high $Z$-score. The cerebellum also showed hypoperfusion (Fig. 2c).

\section{Karger'=}




\section{Case Reports in Neurology}

Case Rep Neurol 2021;13:211-217

DOI: 10.1159/000514243

Obara et al.: Long-Lived Patient with Lafora Disease

We identified a W219R homozygous mutation in exon 1 of the NHLRC1 gene using nextgene sequencing (Illumina MinSeq-based method and VariantStudio analysis) and genomic DNA extracted from her white blood cells (Fig. 3). This mutation was reported previously [3].

\section{Discussion}

We found two important clinical issues. First, our patient with LD showed remarkable frontal hypoperfusion on IMP-SPECT. The findings of functional imaging in LD brain have been reported to be controversial. 18-fluorodeoxyglucose positron emission tomography (FDGPET) revealed posterior hypometabolism in the early stage of LD [4], while FDG-PET in the late stage of LD showed severe and diffuse hypometabolism involving the frontal, temporal, and parietal lobes, and the thalamus [5]. In MRS studies, metabolic abnormalities such as a decrease in NAA/Cr, NAA/Cho, and NAA/myoinositol (mI) in the frontal lobe were demonstrated even in the absence of any structural changes on MRI [6, 7], and a decrease in NAA/mI in the frontal cortex and white matter in LD patients strongly correlated with impairment in executive function on neuropsychological testing indicating frontal lobe involvement [7]. The findings of MRS are consistent with those of IMP-SPECT in our patient in terms of frontal lobedominant impairment in LD.

Second, even in advanced LD, perampanel was effective in controlling seizures of our patient. The seizures in LD commonly become more intractable as it progresses, despite highdose antiepileptic polytherapy [8,9]. In recent years, perampanel, a third-generation antiepileptic drug, has been shown to improve seizures in $\operatorname{LD}[8,10,11]$. Perampanel acts as a noncompetitive alpha-amino-3-hydroxy-5-methyl-4-isoxazolepropionic acid (AMPA) receptor antagonist [12]. Recently, it was reported that GABAergic cortical neurons in a transgenic mouse model of LD were reduced, suggesting that an imbalance between GABAergic and glutamatergic neurons causes convulsion and mental deterioration in LD [13]. This indicates that perampanel may normalize the imbalance of inhibitory to excitatory neurotransmitters in the brain by blocking the glutamatergic AMPA receptors and could control of epilepsy and prevent mental deterioration $[1,8,10,11]$. In fact, two adolescent cases with LD were reported to show improvement in activities of daily living and cognitive function in addition to a marked reduction of seizures after administration of perampanel $[8,11]$. If perampanel was available for our patient in the early stage, we might have been able to prevent mental deterioration.

In conclusion, even at an advanced stage, perampanel was effective in controlling seizures in LD. The frontal hypoperfusion on IMP-SPECT in our patient may reflect mental deterioration in LD. Administration of perampanel in the early stage of LD may prevent both convulsion and frontal hypoperfusion even though we could not find direct evidence in our patient. Further studies should be conducted to confirm the effectiveness of perampanel in LD.

\section{Statement of Ethics}

The parents of the patient provided both oral and written informed consent for the publishing of this report (including publication of images).

\section{Karger'"}




\section{Case Reports in Neurology}

\section{Conflict of Interest Statement}

The authors have no conflicts of interest to declare.

\section{Funding Sources}

The authors did not receive any external funding.

\section{Author Contributions}

Koji Obara was the patient's primary neurologist and drafted the manuscript. Erika Abe performed the genetic testing for the patient. Itaru Toyoshima revised the manuscript and edited the paper.

\section{References}

1 García-Gimeno MA, Knecht E, Sanz P. Lafora Disease: A Ubiquitination-Related Pathology. Cells. 2018 Jul;7(8):E87.

2 Parihar R, Rai A, Ganesh S. Lafora disease: from genotype to phenotype. J Genet. 2018 Jul;97(3):611-24.

3 Singh S, Suzuki T, Uchiyama A, Kumada S, Moriyama N, Hirose S, et al. Mutations in the NHLRC1 gene are the common cause for Lafora disease in the Japanese population. J Hum Genet. 2005;50(7):347-52.

4 Jennesson M, Milh M, Villeneuve N, Guedj E, Marie PY, Vignal JP, et al. Posterior glucose hypometabolism in Lafora disease: early and late FDG-PET assessment. Epilepsia. 2010 Apr;51(4):708-11.

5 Muccioli L, Farolfi A, Pondrelli F, d’Orsi G, Michelucci R, Freri E, et al. FDG-PET assessment and metabolic patterns in Lafora disease. Eur J Nucl Med Mol Imaging. 2020 Jun;47(6):1576-84.

6 Villanueva V, Alvarez-Linera J, Gómez-Garre P, Gutiérrez J, Serratosa JM. MRI volumetry and proton MR spectroscopy of the brain in Lafora disease. Epilepsia. 2006 Apr;47(4):788-92.

7 Pichiecchio A, Veggiotti P, Cardinali S, Longaretti F, Poloni GU, Uggetti C. Lafora disease: spectroscopy study correlated with neuropsychological findings. Eur J Paediatr Neurol. 2008 Jul;12(4):342-7.

8 Schorlemmer K, Bauer S, Belke M, Hermsen A, Klein KM, Reif PS, et al. Sustained seizure remission on perampanel in progressive myoclonic epilepsy (Lafora disease). Epilepsy Behav Case Rep. 2013 Aug;1:11821.

9 Yildiz EP, Yesil G, Ozkan MU, Bektas G, Caliskan M, Ozmen M. A novel EPM2A mutation in a patient with Lafora disease presenting with early parkinsonism symptoms in childhood. Seizure. 2017 0ct;51:77-9.

10 Goldsmith D, Minassian BA. Efficacy and tolerability of perampanel in ten patients with Lafora disease. Epilepsy Behav. 2016 Sep;62:132-5.

11 Dirani M, Nasreddine W, Abdulla F, Beydoun A. Seizure control and improvement of neurological dysfunction in Lafora disease with perampanel. Epilepsy Behav Case Rep. 2014 Sep;2:164-6.

12 Potschka H, Trinka E. Perampanel: does it have broad-spectrum potential? Epilepsia. 2019 Mar;60 Suppl $1: 22-36$.

13 Ortolano S, Vieitez I, Agis-Balboa RC, Spuch C. Loss of GABAergic cortical neurons underlies the neuropathology of Lafora disease. Mol Brain. 2014 Jan;7(1):7. Available from: http://www.molecularbrain.com/content/7/1/7 


\section{Case Reports in Neurology}

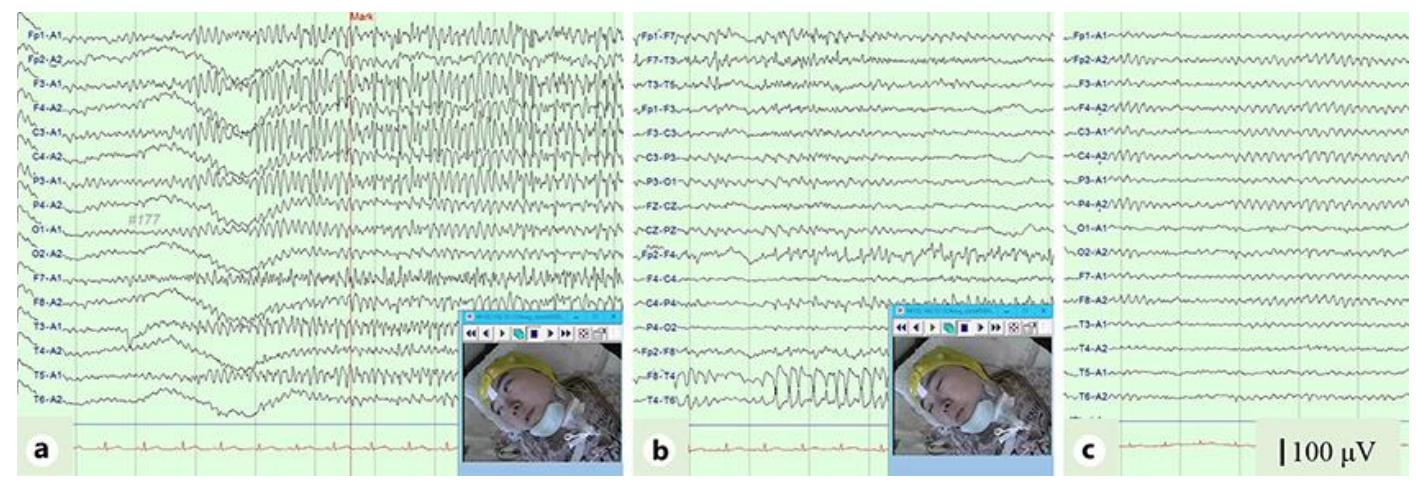

Fig. 1. a, b Video-electroencephalogram (EEG) at the age of 29. a The EEG shows generalized bursts of sharp waves with conjugate deviation and laughing on the monitor. $\mathbf{b}$ Longitudinal bipolar montage. Even after the convulsion stopped and the patient closed her eyes, the focal spikes with phase reversal at the right middle temporal region continue, and then slowly disappear (not shown). c Follow-up EEG taken at the age of 34 shows a slight slowing of the background activity without any obvious spikes. 


\section{Case Reports in Neurology}

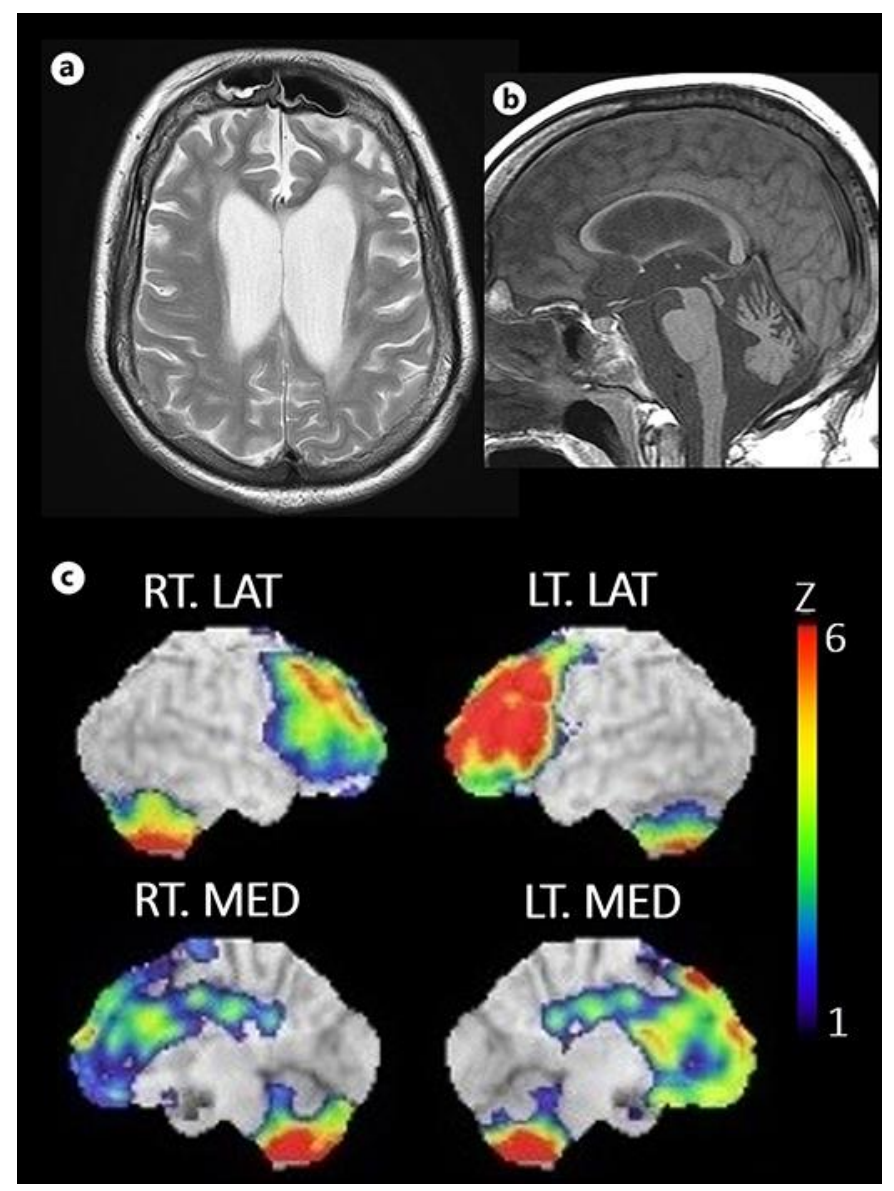

Fig. 2. a Brain magnetic resonance imaging (MRI) at the age of 34 shows frontal lobe-dominant atrophy with dilation of the ventricles and hyperintensity of periventricular white matter on T2-weighted image. b T1-weighted image shows cerebellar atrophy in the sagittal plane. c Images of cerebral blood flow single-photon emission computed tomography using N-isopropyl-p-[123I] iodoamphetamine (IMP-SPECT) at the age of 34. The $Z$-score is higher as the degree of decrease in cerebral blood flow is larger than that of an age-matched normal database. IMP-SPECT reveals significant hypoperfusion in the frontal lobe excluding the motor area and cerebellum. LT, left; LAT, lateral; MED, medial; RT, right. 
Case Reports in Neurology
Case Rep Neurol 2021;13:211-217

(c) 2021 The Author(s). Published by S. Karger AG, Basel www.karger.com/crn

Obara et al.: Long-Lived Patient with Lafora Disease
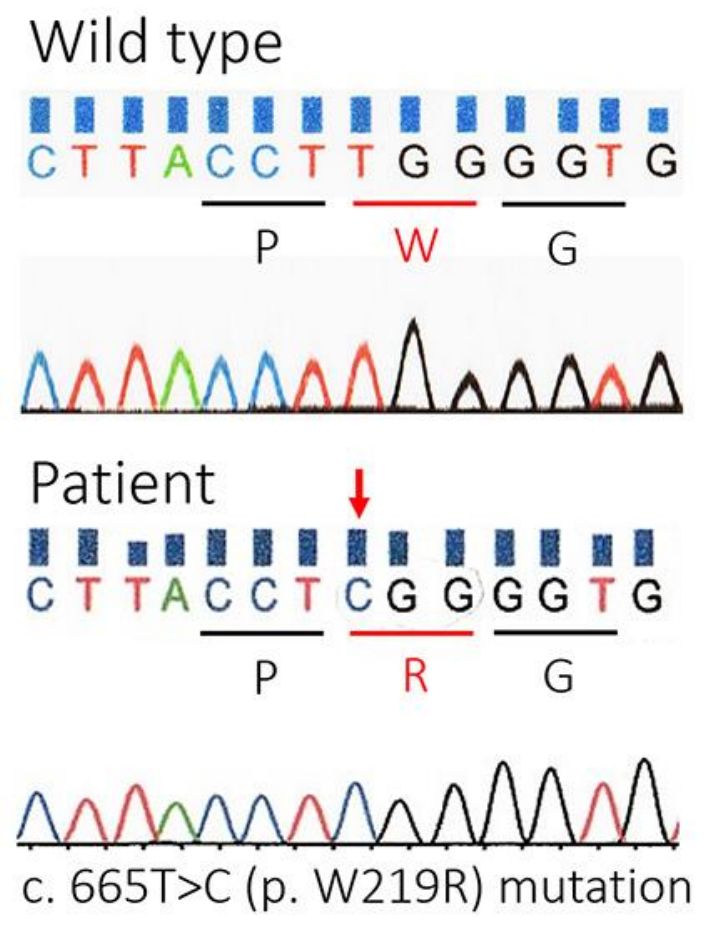

Fig. 3. Sequencing analysis of the patient. Sequencing shows a homozygous missense mutation in the NHLRC1 gene (p. W219R), with a single nucleotide exchange (T-to-C) in exon 1 of the NHLRC1 gene. 